protective genes have evolved which have a survival advantage at times when calories and salt are less abundant, but are disadvantageous when there are unlimited or increased supplies. This goes some way to explaining the marked weight gain and trunkal obesity, insulin resistance and diabetes seen in South Asian immigrants to the UK. Alternatively, building on the Barker hypothesis of intra-uterine growth and its impact on adult health comes the second explanation, the 'adaptation-dysadaptation hypothesis', which investigates the mismatch between 'foetal thrift' and 'postnatal plenty'.

The book also aims to identify areas for treatment and strategies to reduce the epidemic and improve cardiovascular health in this population. The reasons for a higher prevalence of tobacco smoking and a lower quit rate in some ethnic subgroups have been examined well with innovative and culturally-appropriate public health strategies suggested.

TUSHAR RAINA

Specialist Registrar, Royal Hallamshire Hospital

KEVIN S CHANNER

Consultant Cardiologist, Royal Hallamshire Hospital

The good doctor

By Damon Galgut. Atlantic Books, London 2004. 240pp. $£ 7.99$.

This novel is an enthralling, all-consuming and intense read right up to the last page. The two main characters are doctors and many of the sub-plots have a medical slant, but one certainly does not have to be a medic to appreciate and be profoundly moved by the book.

The scene is post-apartheid South Africa and the focus is on the lives of two totally contrasting doctors who find themselves working closely together, indeed sharing a room in a hopeless, run-down hospital. The hospital is 'managed', so to speak, by an incompetent female surgeon and is in one of the old Bantu homelands not far, I suspect, from the Angolan border. One of the two is young, new, energetic, full of ideas and thoroughly enthused about and committed to the 'new' South Africa and what can be achieved. The other is older, has been there a long time, lacks ambition, is not very successful in the eyes of his traditional upper middle-class family, and his marriage has failed. This tale relates the tensions that develop between them and the catastrophic consequences.

The main plot and the various sub-plots deal with violence, corruption and desperation, and are weaved in and out of each other with great skill. There are many unexpected twists and turns; every page is compelling, and many are disturbing and shocking, but the writing is always horribly plausible. The story is brilliantly narrated in its discomforting way, and it was no surprise to learn after I had read it that it had been shortlisted for last year's Booker Prize.

It is a short book, just 200 pages. It is now in paperback and is to be thoroughly recommended.

JM HOLT

Emeritus Physician, Oxford

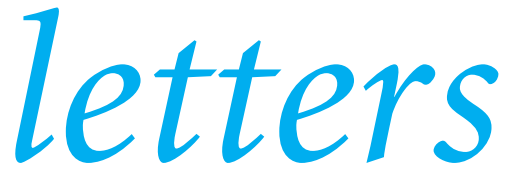

\section{TO THE EDITOR}

Please submit letters for the Editor's consideration within three weeks of receipt of the Journal. Letters should ideally be limited to 350 words, and can be submitted on disk or sent by email to: Clinicalmedicine@rcplondon.ac.uk.

\section{The 2001 guidelines on cardiopulmonary resuscitation}

Editor - The 2001 guidelines on cardiopulmonary resuscitation (CPR) emphasise patient participation in the CPR decisionmaking process. ${ }^{1}$ However, two recent articles in your Journal highlight the difficulties in doing so (Clin Med July/August 2004 pp 424-6; Clin Med July/August 2004 pp 471-2). Over the past five years several studies have shown similar trends, thus exposing the huge gulf between the guidelines and common medical practice. On one hand, the medical profession has been vocal in their disapproval of these guidelines $^{2}$ and on the other, patients have shown no enthusiasm for discussing these issues. ${ }^{3}$ Even the national press has admitted their ignorance on the subject by linking euthanasia to the 'do not resuscitate' order. ${ }^{4}$

The time has come for policy-makers to listen to the profession and revisit guide- lines on cardiopulmonary resuscitation. Emphasis should not only be on political correctness, but also on practicality and improving patient care. Ambiguity surrounding existing guidelines should be rectified by clearly stating that patient engagement in discussing CPR should be at the discretion of the medical team. Models of engaging patients, where appropriate, in end-of-life issues must be an integral part of any revised guidelines.

Policy-makers have the responsibility to present a clear and balanced view, which increases the patient's confidence in the system and is acceptable to doctors and nurses who provide front line care. Failure to do so will harm the very heart of patient care, which these guidelines are intended for.

\section{References}

1 British Medical Association, Resuscitation Council (UK), Royal 
College of Nursing. Decisions relating to cardiopulmonary resuscitation. A joint statement from the British Medical Association, the Resuscitation Council (UK) and the Royal College of Nursing. London: BMA, 2001.

2 Manisty C, Waxman J. Doctors should not discuss resuscitation with terminally ill patients. BMJ 2003;327:614-15.

3 Sivakumar R, Knight J, Devlin C, Keir P et al. Communicating information on cardiopulmonary resuscitation to hospitalised patients. J Med Ethics 2004;30:311-12.

4 Fatal consequences. Editorial. The Times. June 7, 2003.

SA KHAN Consultant Physician Lister Hospital, Herts

\section{Excessive daytime sleepiness and driving: regulations for road safety}

Editor - Perfectly normal people who are tired or bored may fall asleep at the wheel: some $20 \%$ of road accidents are probably caused this way. ${ }^{1}$ Carter and colleagues (Clin Med September/October 2004, pp 454-6) draw attention to the possibility that the risk of causing road accidents may be enhanced by pathological sleep disorders, including narcolepsy, Parkinson's disease and sleep apnoea syndromes. The authors make the important point that individuals with excessive daytime sleepiness may lose their perception or judgement of sleepiness. Furthermore, they suggest that individuals with sleep apnoea do not appreciate that sleepiness could have been the cause of their particular accident. The essence of their paper is that in the case of a diagnosed sleep apnoea syndrome, it is the responsibility of the driver to notify the regulatory authority. But what is the position of other 'at risk' drivers in this pathological group who do not realise that they are susceptible to daytime sleepiness?

This is an excellent opportunity to test 'at risk' subjects using portable ocular monitoring techniques which, by giving an objective measure of sedation and prolonged eye closure while actually at the wheel, have the potential not only to diagnose daytime sleepiness but to prevent sleep-related road accidents. ${ }^{2}$ Eye and eyelid movements can now be measured easily, accurately and non-invasively in a manner that is unusual among neurological tests. ${ }^{2,3}$ While it is a step too far to advocate ocular monitoring of every driver, the high risk group described by Carter et $a l$ is ideal to test the hypothesis that such monitoring may benefit sleepy drivers and may actually reduce the numbers of road accidents.

\section{References}

1 Connor J, Norton R, Ameratunga S, Robinson $\mathrm{E}$ et al. Driver sleepiness and risk of serious injury to car occupants: population based control study. BMJ 2002;324:1125-8.

2 Jones JG, Carpenter RHS. Ocularmonitoring techniques used in anaesthetic sedation may benefit sleepy drivers. Bull $R$ Coll Anaesthetists 2004;28:1414-16.

3 Carpenter RHS. Movements of the eyes (2nd ed). London: Pion, 1988.

JG JONES

Formerly Professor of Anaesthesia Cambridge

RHS CARPENTER

Reader in Oculomotor Physiology Cambridge

Editor - The working group brought together by the Department of Transport (Clin Med September/October 2004, pp 454-6) should be congratulated on bringing this important issue to light. However, I have several concerns about their statement that vocational drivers require a continuous positive airway pressure (CPAP) machine that records 'mask on' time.

These machines are expensive and, outside of specialist centres, we are struggling with our funders to maintain or start even a basic CPAP service. Purchasing only one to two specialist machines for short-term assessments may be obvious for drivers who may alter their short-term behaviour once they know their machines have been changed. Most specialists accept that machine clock-timers only slightly overestimate mask or effective time by $5-10 \%{ }^{1}$ and this will be a cheaper and more practical way of measuring drivers' CPAP usage.

More importantly, we all need different amounts of sleep and it is difficult to remove someone's livelihood if they are using their machine for 3.5 hours per night for very mild disease and have no current daytime symptoms.

Ethically, I have a dilemma between paternalism versus autonomy. I agree that it is the responsibility of drivers to inform regulatory authorities but responsibility must also be firmly placed on them to manage their own treatment. Regular assessment of use may not 'create the supportive environment' for drivers the authors call for - but it could lead to poor users not attending at all. We do need to rely on patient-reporting but then we should consider objective measures of daytime sleepiness or performance on driving simulators for difficult patients. These are likely to be more useful surrogates of driving ability than machine use - but these are not mentioned.

Finally, I agree that patient and public safety can override doctor-patient confidentiality, but in terms of justice we should not only target sleepy drivers. It is only fair that we no longer rely on self-reporting for 'well controlled' epilepsy or 'previous' arrhythmias. Should we monitor tablet compliance and physiology in these other dangerous driving conditions?

\section{Reference}

1 Kribbs NB, Pack Al, Kline LR, Smith PL et al. Objective measurements of patterns of CPAP use by patients with obstructive sleep apnoea. Am J Resp Dis 1993;147:887-95.

KEIR E LEWIS

Senior Lecturer in Respiratory Medicine University of Wales, Swansea

\section{In response}

Editor - The recommendations of the workshop on Excessive Daytime Sleepiness and Driving for use of smart CPAP, as presented in our paper, represent an ideal position in relation to Group Two (bus/lorry) drivers. Such drivers generally have much greater driving exposure than ordinary drivers, work unsocial hours or shiftwork and the consequences of an accident involving a Group Two vehicle are likely to be severe. In practice, we recognise that smart CPAP machines (recording mask-on time) may be restricted in their availability but in high risk cases, where patient compliance is an issue, the availability of objective evidence is seen as a safeguard for both the attending physician and drivers. We acknowledge too that the number of hours of CPAP use to achieve effective daytime symptom relief will vary 